\title{
O processo de mediação: das definições teóricas às propostas pedagógicas
}

\author{
Marilúcia dos Santos Domingos Striquer (UENP)
}

\begin{abstract}
Resumo: Este artigo tem como objetivo revisitar alguns dos preceitos de Vygotsky (2000, 2007, 2008) e seus estudiosos (LEONTIEV, 2004; SFORNI, 2008), a respeito da importância da mediação realizada pelo professor no processo de internalização de instrumentos materiais e psicológicos pelos alunos. A premissa é a de que para que a internalização aconteça é preciso que o sujeito interaja com outros que já são portadores dos instrumentos. Sobre essa perspectiva, apresentamos uma proposta pedagógica constituída com base nos preceitos vygotskyanos.

Palavras-chave: Mediação; internalização de instrumentos; sequência didática.
\end{abstract}

\begin{abstract}
This article aims to revisit some of Vygotsky's precepts (2000, 2007, 2008) and his scholars (LEONTIEV, 2004; SFORNI, 2008), on the importance of mediation accomplished by the teacher in the process of internalization of material and psychological instruments by the students. The premise is that for internalization to take place it is necessary for an the individual to interact with others who have acquired the instruments. From this perspective, we present a pedagogical proposal based on vygotskian precepts.
\end{abstract}

Keywords: Mediation; internalization of instruments; didactic sequence.

\section{Introdução}

Para Vygotsky o conceito de mediação é o elemento central para a compreensão do desenvolvimento e do funcionamento das funções psicológicas superiores ${ }^{1}$, uma vez que o

\footnotetext{
${ }^{1}$ São consideradas funções psicológicas superiores: a atenção, a memória, a imaginação, o pensamento, a linguagem, enfim, o controle consciente do comportamento. Essas funções organizam a vida mental de um indivíduo em seu meio e, de acordo com a Teoria Histórico Cultural de Vygotsky, as funções psicológicas superiores só surgem, se constituem e se desenvolvem nas interações sociais. "A teoria Histórico Cultural é a denominação usualmente dada à corrente psicológica que explica o desenvolvimento da mente humana com 
homem não se relaciona com o mundo de forma direta, se relaciona, fundamentalmente, de forma mediada por instrumentos materiais e psicológicos.

Os instrumentos materiais são físicos como, por exemplo, os utilizados pelos professores em sala de aula: vídeos, slides, equipamentos laboratoriais, entre outros (NASCIMENTO, 2012). E os psicológicos são: os signos, as palavras, os conceitos, os gêneros do discurso, todos aqueles criados pelas sociedades e na cultura ao longo do curso da história humana, os quais, uma vez internalizados, provocam "transformações comportamentais e estabelecem um elo de ligação entre as formas iniciais e tardias do desenvolvimento individual" (VYGOTSKY, 2007, p. 26). Logo, o desenvolvimento se opera por consequência não apenas do uso de instrumentos pelo homem mas também, e sobretudo, pelo fato de que os instrumentos ao carregarem a cultura material, os conhecimentos historicamente elaborados, promovem que o homem internalize operações mentais e físicas para lidar com aquele instrumento e para realizar adaptações que permitem que o instrumento seja utilizado em novas situações. Assim, os instrumentos psicológicos "são ferramentas que auxiliam nos processos psicológicos e não nas ações concretas" como acontece com as ferramentas materiais (VYGOTSKY, 2007, p. 30). Esta é a diferença substancial entre o instrumento material e o psicológico: a maneira como orientam o comportamento humano. $\mathrm{O}$ instrumento material serve para que o indivíduo transforme a natureza externa, por isso é orientado externamente. Enquanto que o psicológico orienta o que é interno, pois se dirige para o controle do próprio indivíduo, auxiliando-o na solução de problemas psicológicos como lembrar, representar, comparar, relatar, planejar, entre outras ações internas ${ }^{2}$.

Vygotsky (2000) define ainda que para internalização dos instrumentos materiais e psicológicos é necessário que o sujeito interaja com outros já portadores desses instrumentos. Exatamente pautados nessa perspectiva que nosso objetivo, neste artigo, é revisitar alguns dos preceitos de Vygotsky (2000, 2007, 2008) e de seus estudiosos (LEONTIEV, 2004; SFORNI, 2008), a fim de compreender, na prática da sala de aula, qual é a

\footnotetext{
base nos princípios do materialismo dialético cujo fundador é L. S. Vygotsky" (LIBÂNEO, J.C.; FREITAS, R.A.M. Vygotsky, Leontiev, Davydov: três aportes teóricos para a Teoria Histórico-Cultural e suas contribuições para a didática. Disponivel em: http://www.sbhe.org.brl. Acessado em 01-03-2011.

${ }^{2}$ De acordo com Friedrich (2012, p. 53), "o conceito de instrumento psicológico foi desenvolvido por Vygotsky em forma de teses no pequeno texto 'O método instrumental em psicologia' (1930) e nos dois primeiros capítulos da obra 'A história do desenvolvimento das funções psíquicas superiores' (1931) " (grifos da autora).
} 
importância da mediação realizada pelo docente, bem como apresentar uma proposta pedagógica constituída com base nos referidos preceitos.

\section{Os preceitos teóricos}

Partindo da afirmativa de Vygotsky (2000) de que para internalização de instrumentos materiais, no sistema educacional formal, é necessário que o aluno interaja com sujeitos portadores desses instrumentos, Sforni (2008) expõem que a mediação passou a ser "sinônimo de ajuda empreendida pelo professor na interação com o aluno", confundida "com a imagem da presença física do professor intervindo nas tarefas que o estudante realiza" (SFORNI, 2008, p. 1). A relação de acompanhamento da criança pelo adulto, apesar de ser um aspecto do desenvolvimento humano, não é considerada o centro desse processo. Muito além da interação sujeito-sujeito, no contexto escolar, a mediação está fundamentada "na relação entre sujeito-conhecimento-sujeito" (SFORNI, 2008, p. 1).

Diferente dos outros animais, a atividade do ser humano é criadora e produtiva. $\mathrm{O}$ homem ao criar um objeto (produto material ou intelectual), cria também o conhecimento sobre sua criação, desenvolvendo, portanto, ciência, tecnologia e arte, que são mediadores culturais. Assim, o relacionamento do homem com os outros homens acontece pela mediação dos conhecimentos científicos, tecnológicos e artísticos objetivados pelas gerações anteriores. Para se apropriar desses conhecimentos, de acordo com Leontiev (2004),

Para fazer deles as suas aptidões, 'os órgãos da sua individualidade', a criança, o ser humano, deve entrar em relação com os fenômenos do mundo circundante através doutros homens, isto é, num processo de comunicação com eles. Assim, a criança 'aprende' a atividade adequada. Pela sua função, este processo e, portanto, um processo de 'educação' ( $p$. 272 - grifos do autor).

Esses "doutros" são outros homens que já se apropriaram dos objetos materiais e intelectuais e que já dominam ações e operações com os mediadores culturais e podem, então, auxiliar a criança, e o adulto, em seu aprendizado. Para exemplificar esse processo, Leontiev (2004) primeiro expõe a apropriação pela criança de um instrumento físico, a colher. A criança em interação com outros indivíduos observa como eles fazem uso desse 
objeto, uso construído historicamente, ou seja, a criança primeiro participa de uma mediação não intencional, não dirigida. Mesmo assim, para efetivamente usar a colher é preciso a mediação intencional, que ocorre quando a mãe, por exemplo, ao alimentar a criança, usa a colher para levar os alimentos até a boca da criança, depois começa a colocar a colher na mão da criança. A mãe além da ação física executa também uma ação verbal, explica à criança como usar o objeto. A criança por fim aprende a utilizar a colher como instrumento que se coloca entre ela e a comida. De acordo com Leontiev (2004), esse exemplo serve também para os processos que envolvem a formação das ações mentais. $E$ a partir disto, orienta Sforni (2008):

Diferentemente da aprendizagem de uma ação motora, na qual a comunicação prática pode ser suficiente para a sua reprodução pela criança, a aprendizagem da leitura, da escrita e do cálculo envolve convenções que não são dadas ao conhecimento somente pela observação do uso que as demais pessoas fazem desses signos. Mesmo estando em um ambiente letrado, o que implica interação constante com letras, palavras, textos, numerais e demais representações gráficas, a comunicação prática com outras pessoas usuárias dessa forma de linguagem não é suficiente para que a criança se aproprie desses elementos mediadores. Nesse caso, para que a apropriação ocorra, a comunicação verbal e prática devem ser intencionalmente dirigidas para a reprodução das ações adequadas com o objeto em pauta, de modo que sejam apropriadas pela criança como instrumentos simbólicos que permitem a ação mental com o mundo circundante. Com o processo de internalização, as marcas externas - os signos - são transformadas em processos internos de mediação do sujeito com o mundo (p. 6-7).

Portanto, o processo de internalização é de responsabilidade do professor, que se realiza quando este transpõe aos estudantes os conteúdos escolares ou conhecimentos historicamente produzidos. Assim, o desenvolvimento do aluno acontece quando ele internaliza os conteúdos escolares (instrumentos psicológicos) e as operações de uso dos conteúdos, isto é, quando o aluno consegue utilizar os conteúdos nas representações dos fatos e das situações reais de uso, dentro e fora da escola. Neste sentido, as práticas intencionalmente dirigidas, os processos de formação acontecem, conforme Sforni (2008, p. 7), por meio de uma "dupla mediação, uma que se refere à relação entre professor e estudantes, outra vinculada à relação entre os estudantes e o conteúdo escolar".

Logo, o conteúdo escolar, de acordo com Vygotsky (2007, p. 104), é "mais do que a soma de certas conexões associativas formadas pela memória, [...] mais do que um simples hábito mental; é um ato real e complexo de pensamento que não pode ser ensinado por 
meio de treinamento". Assim, cada conteúdo escolar possui um grau elevado de abstração, pois não está evidenciado nos fenômenos e nos contextos como acontece com os conceitos cotidianos (espontâneos) (VYGOTSKY, 2000). Por isso, para que seja ensinado, é preciso que o professor elabore ações que intencionalmente dirija a consciência do aluno para cada um dos conteúdos que formam os programas escolares (GALUCH; SFORNI, 2009). Só assim os conteúdos escolares são internalizados dando condições de desenvolvimento às funções superiores de um indivíduo, visto que não podem ser aprendidos por simples "memorização" (VYGOTSKY, 2000), como se fossem algo pronto e acabado. "O desenvolvimento dos conceitos pressupõe o desenvolvimento de muitas funções intelectuais: atenção deliberada, memória lógica, abstração, capacidade para comparar e diferenciar" (VYGOTSKY, 2008, p. 104). Eles são aprendidos em um processo produtivo em que o aluno é colocado em atividade mental de comparação, análise, generalização, abstração e síntese. Assim, de acordo com Hila (2009, p. 8), o aluno passa a tomar "consciência do real uso e valor do conceito, além de conseguir mobilizá-lo em diferentes tarefas".

Esse é também a definição de desenvolvimento adotada pelo Interacionismo Sociodiscursivo (ISD). Segundo Bronckart (2006),

Essas diferentes formas de reorganizar de forma eficaz as significações provenientes das tomadas de consciência, e mais precisamente da capacidade de fazer dialogar de forma útil, no cerne da economia psíquica individual, as diferentes concepções possíveis das ações e dos atores ( $p$. 158).

E é nessa mesma perspectiva que Sforni (2004) afirma que o conteúdo em processo de ensino e aprendizagem deve sempre ser tratado de modo a promover no aprendiz reflexão, análise e generalização, processos mentais imprescindíveis à apropriação conceitual. $E$, para que esses processos aconteçam é imprescindível que o conceito esteja explícito, a fim de que possa ser conscientizado pelos alunos na condição de um instrumento de generalização. Mas isso não significa que o aluno deva saber listar, exemplificar, reproduzir os conceitos escolares, o que é fundamental, conforme postula Sforni (2004, p. 92), é o aluno tomar "posse tanto do nível de consciência neles potencializado quanto da capacidade de organização do pensamento sem os limites empíricos". 
Destacamos ainda que, de acordo com Dolz e Schneuwly (2004), em um processo formativo, é fundamental inserir um indivíduo em formação em práticas intencionalmente dirigidas e que a aprendizagem também seja intencional. Ou seja, o aluno deve estar intencionalmente disposto a se desenvolver.

Um outro elemento essencial para que o processo formativo promova desenvolvimento, conforme Nascimento (2009), é a instauração da prática reflexiva, da participação crítica do aprendiz no processo.

Tudo isto é o que constitui uma adequada formação escolar. De acordo com Leontiev (2004),

A principal característica do processo de apropriação ou de 'aquisição' que descrevemos é, portanto, criar no homem aptidões novas, funções psíquicas novas. É nisto que se diferencia do processo de aprendizagem dos animais. Enquanto este último é o resultado de uma adaptação individual do comportamento genérico a condições de existência complexas e mutantes, a assimilação no homem é um processo de reprodução, nas propriedades do indivíduo, das propriedades e aptidões historicamente formadas na espécie humana (p. 288).

Uma outra questão imprescindível a ser considerada no processo de mediação formativa para criar novas aptidões, novas funções psíquicas para o desenvolvimento do ser humano é a consideração ao conceito de desenvolvimento. Para Vygotsky (2007, p. 103) "aprendizado não é desenvolvimento; entretanto, o aprendizado adequadamente organizado resulta em desenvolvimento mental". Portanto, a aprendizagem oportuniza maior possibilidade de desenvolvimento. Para o autor, existem dois níveis de desenvolvimento: a) o desenvolvimento real: determinado pela capacidade da criança, de um aprendiz de modo geral, resolver sozinho um problema, independente da ajuda de outra pessoa; b) o desenvolvimento potencial: determinado pela constatação de que a criança, ou o adulto, para resolver um problema necessita da orientação de uma outra pessoa que seja mais capaz do que ela. Entre esses dois níveis forma-se a Zona de Desenvolvimento Próximo (ZDP) que é "a distância entre o nível de desenvolvimento real [...] e o nível de desenvolvimento potencial" (VYGOTSKY, 2007, p. 97).

Na ZDP estão as funções que ainda não amadureceram no indivíduo, mas que certamente amadurecerão. Essas funções são denominadas por Vygotsky (2007, p. 98) de "brotos" ou "flores" do desenvolvimento. Ao serem identificados, os brotos estão em fase embrionária, mas logo se desenvolverão, ou desabrocharão, o que acontece, conforme 
Baquero (2001, p. 26), "na participação do sujeito em atividades compartilhadas com outros". Nesse sentido, é exatamente na ZDP que a aprendizagem ocorre, pois ao considerar o conhecimento anterior, aquilo que o aluno já aprendeu, e realizar uma projeção do que ainda pode aprender, da potencialidade para aprender algo novo, que se chega aos processos que estão em estado de formação, de maturação, a ZDP. Nesse sentido, de acordo com Vygotsky (2007), no processo de ensino são necessárias ações do professor que interfiram na ZDP, visto que,

A zona de desenvolvimento proximal pode, portanto, tornar-se um conceito poderoso nas pesquisas do desenvolvimento, conceito este que pode aumentar de forma acentuada a eficiência e a utilidade da aplicação de métodos diagnósticos do desenvolvimento mental a problemas educacionais (VYGOTSKY, 2007, p. 99).

É nesse sentido que Bezerra (2005, p. 39) afirma que o professor, o mais experiente, o responsável institucional pela aprendizagem dos discentes, deve "desafiar, através do ensino, os processos de aprendizagem e desenvolvimento dos alunos". O professor deve trabalhar sobre a ZDP para que aquilo que a criança realiza com a ajuda de um adulto, mais tarde possa realizar de forma independente. Para tanto, defende Chevallard (1991) que os saberes, os conhecimentos científicos/teóricos produzidos pela comunidade científica, devem chegar à sala de aula da mesma forma, com a mesma "roupagem" que foram produzidos.

\section{A transformação dos conhecimentos científicos/teóricos para a sala de aula}

Segundo Chevallard (1991) os saberes produzidos pela comunidade científica devem passar por uma transformação, por uma didatização para chegar à sala de aula, processo denominado pelo autor de Transposição Didática. Tal processo não é realizado de forma direta, da academia à sala de aula, realizado de uma instituição diretamente a outra, pois passa pelo crivo de várias instituições: universidade, órgãos governamentais, redes de ensino, e seus representantes: estudiosos, especialistas, pesquisadores, técnicos, professores. Logo, são os documentos oficiais, como as diretrizes nacionais e estaduais que refletem essas definições, orientando oficialmente o conteúdo a ser ensinado pelo professor em sala de aula. 
Contudo, há ainda outros dois níveis de transposição didática. O segundo nível acontece quando o conteúdo estabelecido pelos documentos oficiais, o saber a ser ensinado, passa pela avaliação da escola, que dentro do que recebeu como prescrito ainda escolhe e define o saber escolar, isto é, quais conteúdos devem ser ensinados pelos professores e aprendidos pelos alunos, levando em consideração as séries de ensino, o tempo de aula destinado à disciplina, a organização dos programas de ensino. E o terceiro nível acontece no momento que o saber escolar é transformado pelo professor em "trabalho interno de transposição" (CHEVALLART, 1991), os quais, com base nas proposições de Bronckart (2006), são designados de conhecimentos efetivamente ensinados, ou seja, dentro do que foi estabelecido pela escola, o professor frente a seus alunos e aos objetos de ensino realiza na prática de sala de aula transformações nos saberes/conhecimentos e efetivamente os ensina aos alunos.

Todo o processo de transposição didática é necessário, visto que os conhecimentos teóricos/científicos, muitas vezes, não são elaborados com o objetivo primeiro de serem ensinados e aprendidos na escola, só que para Nascimento (2011) a dificuldade maior no processo de transposição didática é enfrentada pelo professor quando ele precisa redimensionar o conhecimento estabelecido como conteúdo específico de uma disciplina pelos documentos oficiais e presente nos materiais didáticos para a prática de sala de aula, ou seja, para uma nova situação discursiva. Conforme Nascimento (2011), referindo-se aos instrumentos materiais e psicológicos orientados para os processos de tomada de consciência dos comportamentos, pensamentos e emoções que permitem a autorregulação das ações, essa dificuldade ocorre porque o professor não precisa conhecer apenas os conteúdos específicos de sua disciplina, mas as formas didáticas mais eficientes e eficazes para tornar os objetos de ensino e aprendizagem acessíveis e compreensíveis para os alunos.

Frente à essencialidade da transposição didática, os pesquisadores filiados ao ISD na vertente da Didática das línguas, buscam auxiliar os professores com a transposição da teoria dos gêneros textuais (instrumentos psicológicos ou semióticos) para a sala de aula.

\section{Proposta pedagógica para o ensino dos gêneros como instrumentos semióticos}


A vertente do ISD voltada para os objetos de ensino (SCHNEUWLY; DOLZ, 2004), sugere um processo de transposição didática denominado por eles de "engenharia didática", que é um conjunto de procedimentos modulares que apresentam atividades sistemáticas para ensinar os alunos a se comunicarem oralmente ou por escrito; uma "sequência de módulos de ensino, organizados conjuntamente para melhorar uma determinada prática de linguagem" (DOLZ; SCHNEUWLY, 2004, p. 51).

Para Machado e Lousada (2010, p. 625) tal sequência, denominada pelo ISD de "sequência didática" (SD), "é um artefato que pode se constituir em um instrumento psicológico do trabalho do professor". Mas cabe ao professor inserir os alunos em situações de interação, as quais, evidentemente, devem estar inseridas em problemas de comunicação real (NASCIMENTO, 2009) que aproximem os alunos das práticas discursivas reais. A expressão "aproxime" se justifica porque o gênero trabalhado dentro da sala de aula é sempre uma variação do gênero de referência. A abordagem escolar de uma prática social de referência "tira" o gênero de texto de seu contexto de produção e circulação real, o texto pertencente a um determinado gênero já não mais participa de seu contexto real, onde as finalidades de sua existência são completamente diferentes (SCHNEUWLY; DOLZ, 2004).

Conforme Bazerman, Dionísio e Hoffnagel (2009, p. 10), "não se ensina um gênero como tal e sim se trabalha com a compreensão de seu funcionamento na sociedade e na sua relação com os indivíduos situados naquela cultura e suas instituições". Essa é base da concepção do gênero como um instrumento semiótico para o professor. Tomando o gênero como um instrumento semiótico, o professor é capaz de abstrair a situação imediata de ensino e aprendizagem, não considerando, para simulação de práticas sociais reais, apenas o contexto imediato da sala de aula, mas o que motiva à situação, às práticas realizadas com o gênero fora da sala de aula.

O professor tem consciência de que é apenas em situações de interação, ou nas interações interpessoais, que os alunos realizam junto a seus pares, junto ao professor, que os processos externos concretizados nas atividades entre pessoas se transformam em processo intrapsicológico, onde, segundo Bezerra (2005, p. 39), "a atividade é reconstruída internamente". É por meio de SDs que o aluno pode ir internalizando os gêneros de texto e depois os utilizar conforme suas necessidades individuais.

Entretanto, antes de expor as etapas de uma SD é pertinente abordarmos as atividades a serem realizadas pelo professor antes da elaboração da sequência e durante 
todo o processo de transposição, visto que uma SD deve estar adaptada às capacidades e as dificuldades especificadas dos alunos. Segundo Dolz e Schneuwly (2004), o professor deve sempre se assegurar de:

1. adaptar a escolha de gêneros e de situações de comunicação às capacidades de linguagem apresentadas pelos alunos;

2. antecipar as transformações possiveis e as etapas que poderiam ser transpostas;

3. simplificar a complexidade da tarefa, em função dos elementos que excedem as capacidades iniciais das crianças;

4. esclarecer com os alunos os objetivos limitados visados e o itinerário a percorrer para atingi-los;

5. dar tempo suficiente para permitir as aprendizagens;

6. ordenar as intervenções de maneira a permitir as transformações;

7. escolher os momentos de colaboração com os outros alunos para facilitar as transformações;

8. avaliar as transformações produzidas (DOLZ, SCHNEUWLY, 2004, p. 54).

A seguir apresento as etapas que formam uma sequência didática.

\section{A Sequência Didática}

Conforme Nascimento (2009), com base em Dolz, Noverraz e Schneuwly (2004), a estrutura de base de uma SD pode ser representada pelo esquema: a) apresentação do projeto; b) sensibilização ao gênero; c) primeira produção diagnóstica; d) oficinas: operações para o uso do instrumento; e) produção final - processo de refacção e reescrita; f) final da interação; os textos produzidos pelos alunos são enviados aos destinatários.

Na etapa de apresentação, o professor deve expor aos alunos o projeto de classe, ou seja, o que se pretende realizar com o processo de ensino e aprendizagem do gênero que está sendo abordado (DOLZ, NOVERRAZ, SCHNEUWLY, 2004). Essa ação deve ser realizada de maneira bastante explícita, a fim de que os alunos compreendam em quais situações comunicativas podem agir fora da escola com o gênero proposto, e qual a situação real de comunicação que eles participarão com a produção final. Portanto, nessa etapa, o aluno recebe informações a respeito da função/finalidade social comunicativa do gênero, de onde veio o gênero (historicidade), os temas que podem ser abordados; a quem se dirige (destinatários); que formato assume o gênero (carta, folheto, conto, etc.), se o 
gênero é oral ou escrito. Assim o contexto de produção, o de circulação, a funcionalidade social, a estrutura formal do gênero são abordados.

A etapa de produção de um primeiro texto pelos alunos é o procedimento que permite ao professor identificar as capacidades que os discentes já têm, quais suas potencialidades, e quais os pontos que necessitam de desenvolvimento. O professor, com base nos textos produzidos pelos alunos, obtém informações para diferenciar e até mesmo individualizar, se necessário, seu planejamento de ensino (DOZ, NOVERRAZ, SCHNEUWY, 2004). É a partir da primeira produção que os módulos se constituem, os quais são denominados por Nascimento (2009) de oficinas.

Importante ainda expormos que a primeira produção por ser um instrumento para uma primeira avaliação formativa, o professor não precisa constituir uma situação real de comunicação, podendo estabelecer, por exemplo, um destinatário fictício para os textos produzidos pelos alunos. Por assim se constituir, a ideia é a de que a primeira produção não receba nota avaliativa.

Os módulos ou oficinas, os quais são, como mencionado, elaborados pelo professor conforme as necessidades, dificuldades e potencialidades identificadas na produção do aluno. São oficinas de trabalho com as especificidades levantadas, e devem, principalmente, conforme Dolz, Noverraz e Schneuwly (2004, p. 105), "variar os modos de trabalho", ou seja, diversificar os exercícios e as atividades de leitura e escrita para que os alunos tenham "acesso, por diferentes vias, às noções e aos instrumentos, aumentando, desse modo, suas chances de sucesso".

A etapa da produção final acontece quando o aluno tem a oportunidade de pôr em prática tudo que aprendeu e ainda avaliar seu desenvolvimento. É também quando o professor avalia as produções do aluno como produto final e, sem dúvida, como processo. Ou seja, momento de realizar uma avaliação somativa.

De acordo com Saito e Nascimento (2010), algumas concepções são necessárias para um melhor entendimento de como trabalhar com o processo de SD. A primeira é a de aprendizagem como um processo espiralado, ou chamada por Saito e Nascimento (2010, p. 41), de aprendizagem em espiral, que é "o contrário daquele ensino linear, em que se trabalha com um tipo de texto e depois se passa a outro, e outro, subindo degraus em dificuldades". No lugar dessa linha reta, o ensino em espiral é uma curva em que a variedade de gêneros de texto seja trabalhada em todas as séries de ensino: "distanciando-se 
gradualmente do ensinado, para voltar a abordá-lo mais adiante, segundo uma abordagem mais adequada ao momento e ao progresso do aluno" (p. 41). Na orientação de Dolz, Noverraz e Schneuwly (2004), o que vai variar de um nível escolar para o outro é o aprofundamento que o professor dá sobre as dimensões ensináveis do gênero, que se faz diante do avanço do aluno. Assim, a complexificação acontece a partir do que o aluno já conhece, já sabe sobre o gênero. A partir disso, há a promoção de uma expansão e transformação para o novo. Por isso, o encaminhamento de Dolz, Noverraz e Schneuwly (2004) é para que o aluno produza um primeiro texto e só então o professor elabore os módulos de trabalho, porque o primeiro texto é instrumento para diagnóstico do que o aluno já sabe.

A base de constituição do processo de aprendizagem em espiral nasce do pensamento vygotskyano a respeito da Zona de Desenvolvimento Próximo (ZDP). Por meio da primeira produção, o professor analisa o nível de desenvolvimento real do aluno e o nível de desenvolvimento potencial, aquilo que ainda pode ser amadurecido no aluno e com o trabalho proposto, certamente amadurecerá (VYGOTSKY, 2007).

Uma segunda noção importante para o trabalho com as SDs é a da importância do trabalho com textos autênticos, isto é, textos que circulam na sociedade, para que possam ser referências para o gênero em abordagem na sala de aula. Na escola, o que tradicionalmente ocorre, segundo Pasquier e Dolz (1996), é a utilização de textos ad hoc, ou seja, textos criados para a circunstância específica de ensino e aprendizagem em sala de aula, às vezes, buscando uma simplificação dos textos sociais ou uma higienização, no sentido do texto conter exatamente os elementos que se pretende trabalhar, e muitos desses elementos para que sirvam de exemplos. São os textos sociais, aqueles produzidos em contextos sociais reais e específicos, que devem ser trazidos para a sala de aula, pois o papel da escola é ensinar o aluno a interpretar e produzir textos dentro e fora da sala de aula.

E ainda um outro ponto, é a indissociabilidade entre o trabalho com a leitura e a produção textual. A leitura sempre concede informações e também referências (modelos) à escrita. E, a refacção, ou reescrita de textos, deve ser compreendida como parte constitutiva do processo de produção, uma vez que é um retorno do produtor ao texto para intervenções e melhorias. Contudo, de acordo com Dolz, Gagnon e Decândio (2010, p. 27), 
"a fórmula que diz que escrever é re-escrever não se aplica unicamente aos alunos em curso de aprendizagem da escrita, mas a todos os que escrevem".

Imprescindível destacar após a abordagem ao conceito, função e procedimentos de elaboração das SDs, que, além desse processo de ensino dos gêneros textuais, existem muitos outros instrumentos que os professores podem construir e utilizar para intervir, detectar e diagnosticar dificuldades, monitorar a aprendizagem e promover o desenvolvimento das capacidades de linguagem dos alunos, mas, segundo defende Nascimento (2009, p. 7), o fato de que "ensino da língua deve dar-se através de gêneros de textos é hoje um consenso entre linguistas teóricos e aplicados que se referem ao estudo dos gêneros como uma área interdisciplinar muito fértil". Também é consensual que as propostas pedagógicas que ensinam a língua através de gêneros de texto dependem, conforme defende Lopes-Rossi (2005), de um professor "mediador de conhecimentos, orientador e parceiro dos alunos nas produções", de "um contexto que favoreça a interação entre todos os envolvidos", bem como a concepção de "avaliação dos alunos pelo envolvimento ao longo do processo (e não apenas em uma ou outra atividade)" (LOPESROSSI, 2005, p. 89).

\section{Referências bibliográficas}

BAQUERO, R. Vygotsky e a aprendizagem escolar. Porto Alegre/RS: Artmed, 2001.

BAZERMAN, C.; DIONISIO, A.P.; HOFFNAGEL, J.C. (orgs.). Gêneros textuais, tipificação e interação. Tradução e adaptação de Judith Chambliss Hoffnagel. 3 ed. São Paulo: Cortez, 2009.

BEZERRA, M.A. Ensino de língua portuguesa e contextos teórico-metodológicos. In: DIONISIO, A.P.; MACHADO, A.R.; BEZERRA, M.A. (orgs.). Gêneros textuais \& ensino. 4. ed. Rio de Janeiro: Lucerna, 2005, p. 37-46.

BRONCKART, J.P. Atividade de linguagem, discurso e desenvolvimento humano. Tradução Anna Rachel Machado, Maria de Lourdes Meirelles Matencio. Campinas/SP: Mercado das Letras: 2006.

CHEVALLARD, Y. La Transposition Didactique. Grenoble: La Pensée sauvage, 1991. DINIZ, J.E. Formação de professores: pesquisa, representações e poder. Belo Horizonte/MG: Autêntica, 2000.

DOLZ, J.; SCHNEUWLY, B. Gêneros e progressão em expressão oral e escrita: elementos para reflexões sobre uma experiência suiça (francófona). In: SCHNEUWLY, B.; DOLZ, J. e 
colaboradores. Gêneros orais e escritos na escola. Tradução e organização Roxane Rojo e Glaís Sales Cordeiro. Campinas/SP: Mercado das Letras, 2004, p. 41-70.

; NOVERRAZ, M.; SCHNEUWLY, B. Sequências didáticas para o oral e a escrita: apresentação de um procedimento. In: SCHNEUWLY, B.; DOLZ, J. e colaboradores. Gêneros orais e escritos na escola. Tradução e organização Roxane Rojo e Glaís Sales Cordeiro. Campinas/SP: Mercado das Letras, 2004, p. 95-128.

; GAGNON, R.; DECÂNDIO, F. Produção escrita e dificuldades de aprendizagem. Tradução Fabrício Decândio e Anna Rachel Machado. Campinas/SP: Mercado de Letras, 2010.

GALUCH, M.T.B.; SFORNI, M.S.F. Aprendizagem conceitual e apropriação da linguagem escrita. Estudos em Avaliação Educacional, São Paulo, v. 20, n. 42, p. 111-124, jan. /abr. 2009.

HILA, C.V.D. Gêneros textuais e a formação dos professorandos no curso de Letras. In: I Congresso Latino-Americano sobre formação de professores de línguas, 2006, Florianópolis/SC. Anais... Florianópolis/SC: Universidade Federal de Santa Catarina, nov./ 2006, p. 112-129.

KLEIMAN, A.B. Letramento e suas implicações para o ensino de língua materna. Signo. Santa Cruz do Sul/RS, v. 32, n. 53, p. 1-25, dez, 2007.

LEONTIEV, A.N. O desenvolvimento do psiquismo. 2.ed. São Paulo: Centauro, 2004

LOPES-ROSSI, M.A.G. Gêneros discursivos no ensino de leitura e produção de textos. In: KARWOSKI, A.M.; GAYDECZKA, B.; BRITO, K.S. (orgs.). Gêneros textuais: reflexões e ensino. Palmas e União da Vitória/PR: Kaygangue, 2005, p. 79-93.

MACHADO, A.R.; LOUSADA, E.G. A apropriação de gêneros textuais pelo professor: em direção ao desenvolvimento pessoal e à evolução do 'méttier'. Linguagem em (Dis)curso. Palhoça/SC, v. 10, n. 3, p. 629-633, set/dez. 2010.

MAGALHÃES, M.C.C. A linguagem na formação de professores como profissionais reflexivos e críticos. In: MAGALHÃES, M.C.C (org.). A formação do professor como um profissional crítico: linguagem e reflexão. Campinas/SP: Mercado de Letras, 2004, p. 45-62.

; LIBERALI, F.C. O Interacionismo Sociodiscursivo em pesquisas com formação de educadores. Calidoscópio. Unisinos-Tubarão/SC, vol. 2, n. 2, p. 105-112, jul/dez 2004. NASCIMENTO, E. L. Gêneros textuais: da didática das línguas aos objetos de ensino. São Carlos/SP: Editora Claraluz, 2009.

A dupla semiotização dos objetos de ensino-aprendizagem: dos gestos didáticos fundadores aos gestos didáticos específicos. Signum. Universidade Estadual de LondrinaLondrina/PR, n. 1, julho 2011. 
Mediações formativas na perspectiva do Interacionismo sociodiscursivo. Mesa Redonda: Práticas Docentes na educação profissional: perspectivas e desafios. II Seminário das áreas de conhecimento da base comum: aprendizagens na educação profissional técnica e tecnológica. Dourados-MT: Instituto Federal de Educação, Ciência e Tecnologia (UFMT), 2012, cópia interna.

PASOUIER, A.; DOLZ, J. Un decálogo para enseñar a escribir. In: CULTURA y Educación, Madrid: Infancia y Aprendizaje, v. 2. Tradução provisória de Roxane Helena Rodrigues Rojo, p. 31-41, 1996.

SAITO, C. L.N.; NASCIMENTO, E.L. Os gêneros como instrumento para o ensino e aprendizagem da leitura e da escrita. In: MENEGASSI, R.J.; SANTOS, A.R.; RITTER, L.C.B. (orgs.). Escrita e ensino. 2. ed. Formação de professores -EAD, v. 42. Maringá/PR: Eduem, 2010, p 25-58.

SCHNEUWLY, B.; DOLZ, J. Os gêneros escolares: das práticas de linguagem aos objetos de ensino. In: SCHNEUWLY, B.; DOLZ, J. e colaboradores. Gêneros orais e escritos na escola. Tradução e organização Roxane Rojo e Glaís Sales Cordeiro. Campinas/SP: Mercado das Letras, 2004, p. 71-92.

SFORNI, M. S. F. Aprendizagem e Desenvolvimento: o papel da mediação. In: Vera Lúcia Fialho Capellini; Rosa Maria Manzoni. (Org.). Políticas públicas, práticas pedagógicas e ensino-aprendizagem: diferentes olhares sobre 0 processo educacional. BauruUNESP/FC/SP: Cultura Acadêmica, 2008.

VYGOTSKY, L.S. A construção do pensamento e da linguagem. São Paulo: Martins Fontes, 2000.

A formação social da mente: o desenvolvimento dos processos psicológicos superiores. Organizadores Michael Cole et al. Tradução José Cipolla Neto, Luís Silveira Menna Barreto, Solange Castro Afeche. 7. ed. São Paulo: Martins Fontes, 2007.

Pensamento e linguagem. Tradução Jefferson Luiz Camargo. 4. ed. São Paulo: Martins Fontes, 2008.

\footnotetext{
i Marilúcia dos Santos Domingos Striquer. Doutora em Estudos da Linguagem. Professora adjunta da Universidade Estadual do Norte do Paraná (UENP).

marilucia@uenp.edu.br
} 